analytical data for an isopropylamine derivative, Cavallito et al. assigned to their product the molecular formula $\mathrm{C}_{15} \mathrm{H}_{20} \mathrm{O}_{5}$. X-ray crystallographic analysis of the sample of (I) in our possession, which was in the form of orthorhombic needles, gave the following results : $a=12.3 \mathrm{~A} . ; b=11.0 \mathrm{~A} . ; c=13.8 \mathrm{~A}$.; space group $P 2_{1} 2_{1} 2 ; n=4$; density $1 \cdot 19$; molecular weight $337 \pm 12$ (or a submultiple of this). This molecular weight corresponded to a molecular formula $\mathrm{C}_{18} \mathrm{H}_{24} \mathrm{O}_{6}$, and suggested that (I) and (II) might be isomeric.
E. P. ABRAham
A. E. JosEPH
D. M. Crowfoot E. M. OsBorN

Sir William Dunn School of Pathology

and Department of Crystallography, Oxford.

${ }^{1}$ Osborn, E. M., Brit. J. Exp. Path., 24, 227 (1943).

- Heatley, N. G., Biochem. J., 38, 61 (1944).

' Jacobs, W. A., Hoffmann, A., and Gustus, E. L., J. Biol. Chem., 70, $1(1926)$.

‘Thiele, J., Ann., 819, 144 (1901).

-Cavallito, C. J., Bailey, J. H., and Kirchner, F. K., J. Amer. Chem. Soc., 67, 948 (1945).

\section{Factors Contributing to the Bacteriolytic Effect of Species of Myxococci upon Viable Eubacteria}

Aцтночgh the lytic effect of certain myxobacteria upon the true bacteria (eubacteria) has been known for some years ${ }^{1-4}$, the mechanism of the process is imperfectly understood, and no one seems hitherto to have studied the possible production of antibiotic substances by the first-named group of micro. organisms. One of us (B. N. S.) has recently shown ${ }^{5}$ that some species of the Myxococcaceæ undoubtedly cause lysis of living as well as dead bacteria, particularly upon solid non-nutrient media, but attempts to grow the lytic strains in suspensions of eubacteria in very dilute salt solution succeeded only when the latter were mostly non-viable. A possible explanation of this apparent anomaly is that the growth of the myxococcus concerned, upon dead bacteria or their products of disintegration, results in the production of a true non-enzymic antibiotic substance capable of killing viable eubacteria and so rendering them susceptible to lysis by the exocellular enzymes previously elaborated by the growing myxococci. If, therefore, an inoculum of myxococcal microcysts is made into a suspension of chiefly viable bacteria in a liquid, the minute amount of growth which can take place quickly upon the fow dead bacteria will be insufficient to produce a high enough uniform concentration of antibiotic substance to kill any viable bacteria, and so growth ceases; but if an inoculation is made upon a dense mass of eubacteria on a solid medium, diffusion of metabolites is hindered and a high enough concentration of antibacterial substance is built up in the vicinity of the inoculum to kill some of the'viable cells in that region and so enable growth of the myxobacterium to continue with progressive lysis of the eubacterial mass. We present below some evidence concerning the separation of the soluble non-enzymic antibiotic substance from the accompanying exocellular lytic enzymes which are active against non-viable bacteria only.

In one instance, namely, a strain of $M$. virescens derived from soil, the separation has been achieved by the simple expedient of growing the organism in a cell-free liquid medium of simple composition and isolating a crude non-enzymic antibiotic substance, soluble in certain organic solvents, from the metabolic liquid by chemical means. This medium contained the amino-acids of a total acid hydrolysate of casein (c. 1 per cent) as sole source of carbon and nitrogen, and the optimum period of incubation for production of antibiotic substance was about ten days at $24^{\circ} \mathrm{C}$. Incubation for a further fourteon days resulted in the total disappearance of antibacterial activity against Staphylococcus aureus for example, but the metabolic liquid still had good proteolytic activity against gelatin or the proteins of nutrient broth, and also bacteriolytic powers against dead bacteria, particulärly of Gram-negative species. It had no action at all against suspensions of viable eubacteria made from a young nutrient agar slope. On the other hand, the crude antibiotic substance, which appeared to be associated with the valineleucine fraction of the monamino-mono-carboxylic acids of the casein hydrolysate, had no proteolytic or bacteriolytic powers whatever. The most active preparation so far obtained completely inhibited the growth of Staphylococcus aureus at a concentration of 0.008 per cent in heart broth, but as this alcohol-soluble material consisted chiefly of valine and the leucines, the real antibiotic substance is probably of much greater activity than this.

It is a curious fact that the antibiotic substance acts much less powerfully upon Gram-negative than upon Gram-positive viable bacteria, while the reverse is true for the action of the lytic (proteolytic) enzymes upon dead bacteria. Hence it is not surprising that myxococci seem often to grow almost equally well on either kind of eubacteria, when presented as a partly living substrate upon solid media.

Our results will be reported in more detail elsewhere, but it is worth emphasizing a fact not generally known, namely, that myxococci can often be grown without difficulty in simple cell-free liquid media containing nothing more complex than amino-acids, and hence are amenable to the usual procedures employed for the study of the metabolism of moulds, yeasts and eubacteria, including the production of antibiotic substances.

Division of Biochemistry,

A. E. OXFORD

London School of Hygiene and Tropical Medicine, University of London.

Department of Soil Microbiology, Rothamsted Experimental Station, Harpenden, Herts.

Oct 29 .

1 Pinoy, P. E., Ann. Inst. Pasteur, 35, 487 (1921).

2 Solntzeva, L. I., Microbiologia (U.S.S.R.), 8, 700 (1939).

${ }^{3}$ Beebe, Iowa State College J. Sci., 15, 319 (1941).

- Snieszko, S. F., McAllister, J., and Hitchner, E. R., Quart. Bull. Polish Inst. Arts and Sci. in America, 1, 651 (1943).

${ }^{5}$ Singh, B. N., J. Gen. Microbiol., in the press.

\section{Pterygospermin: the Antibacterial Principle of Moringa pterygosper ma, Gaertn.}

Tне discovery and use of penicillin and streptomycin has led to a search for similar antibiotics in other fungi and in higher plants. Systematic studies conducted in these laboratories ${ }^{1}$ have shown the possibilities of a number of plant materials, reported in Indian medicine, which contain antibiotic substances effective against both Gram-positive and 